http://jmscr.igmpublication.org/home/

ISSN (e)-2347-176x ISSN (p) 2455-0450

crossref DOI: https://dx.doi.org/10.18535/jmscr/v8i7.28

Journal Of Medical Science And Clinical Research

\title{
A Case Report on Tuberous Sclerosis Complex
}

Authors

\section{Gunda Mounika', Juvvadi Sharvani Rao', M.A Wahab Sufiyaan Osmani , Dr Thatikonda Anil Kumar ${ }^{2 *}$, Dr Kadarla Rohith Kumar ${ }^{3}$}

${ }^{1}$ Pharm D (Intern), Department of Pharmacy Practice, Sree Chaitanya Institute of Pharmaceutical Sciences,

Thimmapur, Karimnagar

${ }^{2}$ Neurologist, Vijaya Hospital, Karimnagar

${ }^{3}$ Asst Professor, Department of Pharmacy Practice, Sree Chaitanya Institute of Pharmaceutical Sciences,

Thimmapur, Karimnagar, Telangana, India-505527

*Corresponding Author

Dr Thatikonda Anil Kumar

Neurologist, Vijaya Hospital, Karimnagar, India

\begin{abstract}
Tuberous sclerosis complex (TSC) is a rare, multisystem, autosomal dominant neurocutaneous syndrome characterized by tumorigenesis and is associated with neurologic and behavioral abnormalities. The frequency of TSC has been estimated to be 1 in 10,000 live births and is about a third as common as neurofibromatosis type 1. It is clinically characterized by the triad of epilepsy (EPI), intellectual disability (LOI), and adenoma sebaceum. Here we are presenting a 5 years old male child born of a consanguineous marriage brought to the neurophysician after an attack of seizures, from the explanation of his parents the seizures type was confirmed as GTCS lasting for 1-2 minutes involving both upper and lower limbs with eyes rolling upwards and forth from the mouth. Physical examination revealed characteristic skin lesions and imaging reports of brain showed abnormal tubers, together confirmed Tuberous sclerosis Complex. As it is a multisystem disorder, careful clinical observation is essential, patients affected are advised for regular follow up and counselling.

Keyword: Tuberous Sclerosis Complex, Refractory Seizures, Subependymal Nodules.
\end{abstract}

\section{Introduction}

Tuberous sclerosis complex (TSC) is a rare, multisystem, autosomal dominant syndrome characterized by tumorigenesis and is associated with neurologic and behavioral abnormalities. TSC was first identified by German pathologist Friedrich Daniel von Recklinghausen, in 1862, in a baby with cardiac myotomas and sclerotic brain lesions who died shortly after birth. ${ }^{1}$ It was better defined in 1880 by French neurologist Désiré-Magloire Bourneville as "tuberous sclerosis of the cerebral convolutions"; hence, the disease was named "Bourneville's disease" after him. His patient reportedly had seizures, intellectual disability, and renal angiomyolipomas (AMLs) in the form of "hard masses, one the size of a walnut". The first use of the term tuberous sclerosis complex was by 
Sylvan Moolten in 1942. In 1972, SpanishAmerican neurologist Manuel Rodriguez Gomez established the first diagnostic criteria for TSC, and he has since been viewed as the father of TSC in the USA. ${ }^{2}$ TSC is classified as a phakomatosis (neurocutaneous disorder) and which is characterized by the presence of glial cell tumors arising in the cerebral hemispheres and retina. ${ }^{3}$ It is clinically characterized by the triad of epilepsy (EPI), intellectual disability (LOI), and adenoma sebaceum (A), therefore, encompassing these features Sherlock coined the term EPILOIA. ${ }^{4}$ The frequency of TSC has been estimated to be 1 in 10,000 live births and is about a third as common as neurofibromatosis type $1 .^{5}$ It is a multisystemic disorder which becomes perceptible only in late childhood, limiting the expediency for early diagnosis in infancy. ${ }^{6}$

\section{Case Report}

A 5 years old male child born of a consanguineous marriage brought to the neurophysician after an attack of seizures, from the explanation of his parents the seizures type was confirmed as GTCS lasting for 1-2 minutes involving both upper and lower limbs with eyes rolling upwards and froth from the mouth.

\section{Examination of Skin Revealed:}

1. Hypomelanotic macules (on face, chest and right axilla)

2. Facial angiofibromas.

His laboratory investigations (blood and urine test) were found to be normal, chest X-ray was normal. Renal function test and serum electrolytes were found to be normal. No sonographic abnormality detected in USG abdominal scan.

\section{MRI Brain Showed:}

1. Cortical and subcortical tubers (bi frontal, temporal and occipital regions)

2. Subependymal nodules noted in lateral ventricles.
Physical examination revealed characteristic skin lesions and imaging reports of brain showed abnormal tubers, together confirmed Tuberous sclerosis Complex. He was prescribed with an anti epileptic drug Levetiracetam $250 \mathrm{mg}$ /day (tablet is split into two halves, one half is taken in morning and the other half at night).Parents of the child was counselled about the proper health care measurements to be taken and recommended for regular follow up.

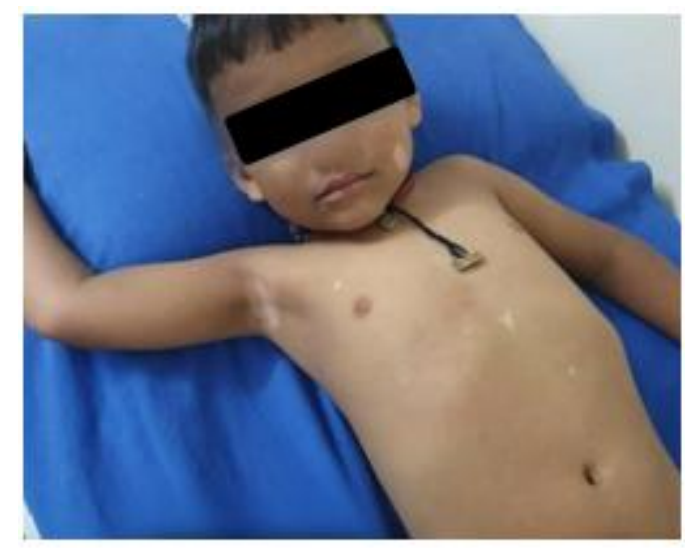

Figure 1A: Hypomelanotic Macules

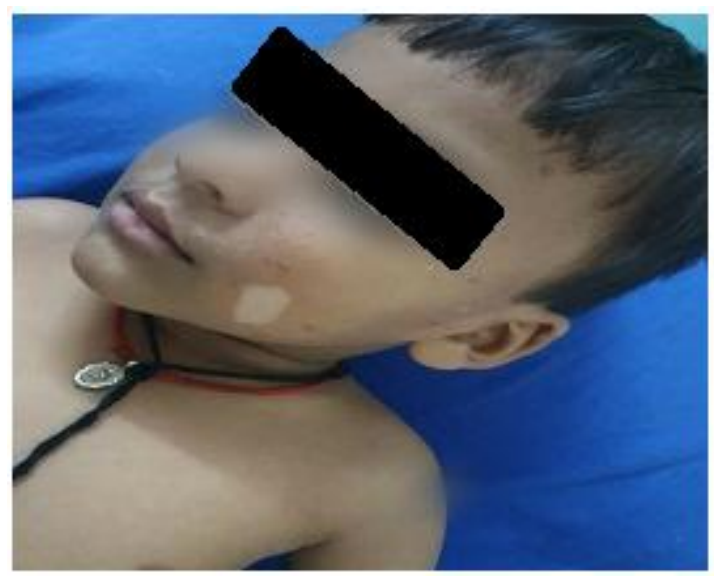

Figure1B: Facial angifibromas 


\section{JMSCR Vol||08||Issue ||07||Page 141-145||July}

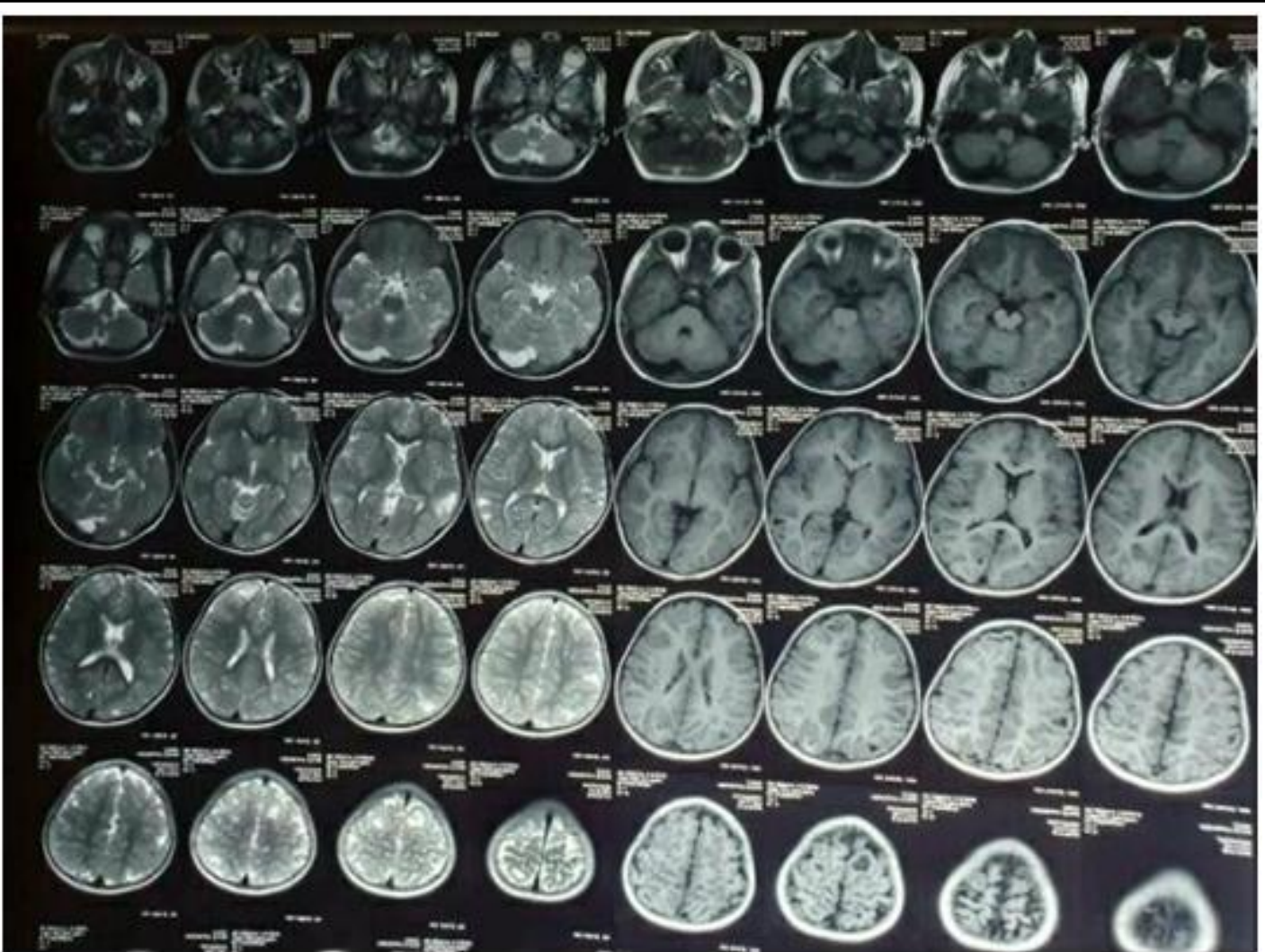

Figure 2A: T1 and A2 Axial MRI brain showing hypo and hyperintense Cortical tubers in the bifrontal, temporal and occipital region

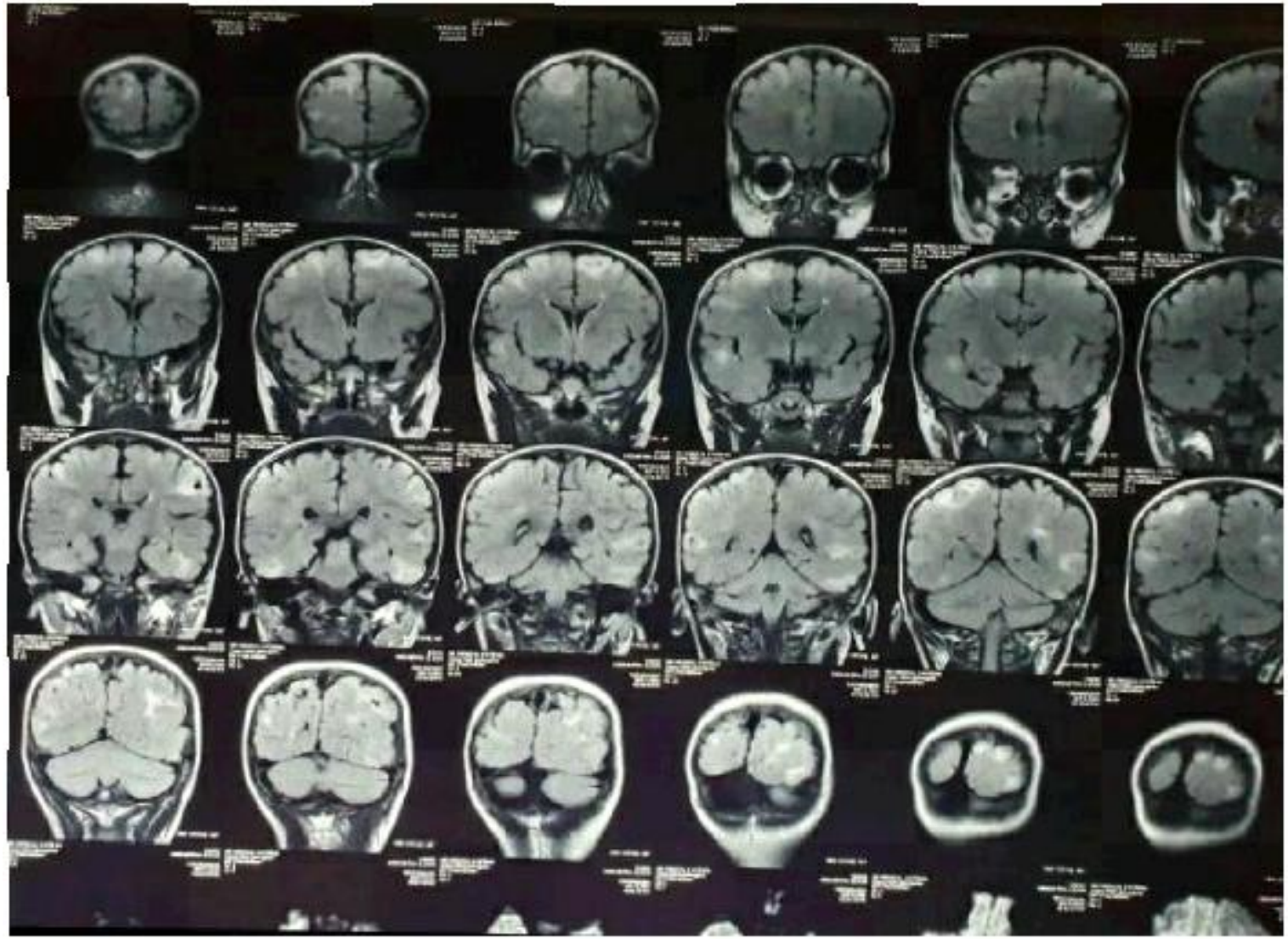

Figure 2B: Flair showing Hyperintense Cortical and Subcortical Tubers in the Bifrontal, Temporal region 


\section{Discussion}

TSC is characterized by the development of unusual tumor-like growths (hamartomas) in brain, skin, retina, and viscera. The term "tuberous sclerosis" refers specifically to the presence of multiple sclerotic masses scattered throughout the cerebrum. The diagnosis of TSC is based on the identification of hamartomas in more than one organ system. $^{7}$

TSC is an autosomal dominant disorder with nearly complete penetrance but variable expressivity. The abnormal genes have been localized to one of two sites, the long arm of chromosome 9 (9q34), designated as TSC 1 (encoding hamartin), and the short arm of chromosome 16 (16p 13.3) designated as TSC 2 (encoding tuberin). These gene products form a tumor suppressor complex which drives Rheb (Ras homolog enriched in brain) a member of Ras superfamily into the inactive guanosine diphosphate-bound state. When Rheb is in the guanosine triphosphate-bound active state, it stimulates the mammalian target of rapamycin (mTOR), an evolutionarily conserved protein kinase and a major effector of cell growth. The mutations in these genes result in constitutive mTOR activation leading to the formation of various growths and hamartomas in various organs of the body. ${ }^{8}$ In a study conducted on 325 TSC individuals, $17 \%$ of the mutations were found in the TSC1gene, $50 \%$ in the TSC2gene, $4 \%$ unclassified variants, and $29 \%$ with no identifiable mutations. ${ }^{9}$

\section{Clinical Diagnostic Criteria Major Feature:}

1. Hypomelanotic macules $(\geq 3$, at least 5-mm diameter) 2.Angiofibromas $(\geq 3)$ or fibrous cephalic plaque 3.Ungual fibromas $(\geq 2)$ 4.Shagreen patch 5.Multiple retinal hamartomas 6.Cortical dysplasias* 7.Subependymal nodules 8.Subependymal giant cell astrocytoma 9.Cardiac rhabdomyoma 10.Lymphangioleiomyomatosis $\quad(\mathrm{LAM}) \dagger$ 11.Angiomyolipomas $(\geq 2)$

\section{Minor Feature:}

1. "Confetti" skin lesions 2.Dental enamel pits
(>3) 3. Intraoral fibromas $(\geq 2) 4$. Retinal achromic patch 5.Multiple renal cysts 6.Nonrenal hamartomas

\section{Definite Diagnosis:}

Two major features or one major feature with $\geq 2$ minor features

\section{Possible Diagnosis:}

Either one major feature or $\geq 2$ minor features

Includes tubers and cerebral white matter radial migration lines.

A combination of the two major clinical features (LAM and angiomyolipomas) without other features does not meet criteria for a definite diagnosis. ${ }^{10}$

The most common oral manifestations of TSC are fibromas, gingival hyperplasia, and enamel hypoplasia (in almost $100 \%$ of these patients and is associated with an increased risk of caries). The other features include hamartomatous rectal polyps, nonrenal hamartomas, multiple renal and bone cysts, high arched palate, bifid uvula, cleft palate, delayed dental eruption, and presence of diastemas. Our case presented with three major features - facial angiofibromas, Köenen tumors and subependymal nodules and two minor features- gingival fibromas and enamel hypoplasia.

The management of these patients is often multidisciplinary involving the neurosurgeon, neurologist, nephrologist, pulmonologist, cardiologist, ophthalmologist, and the genetic counselor. Surgery including dermabrasion and laser treatment may be useful for the treatment of skin lesions. Intervention programs including special schooling and occupational therapy may benefit individuals with special needs and developmental concern.

Drug therapy for some of the manifestations of TSC is currently in the developmental stage. Recent trials have shown the use of topical $0.1 \%$ rapamycin on facial angiofibromas. The use of inhibitors of mTOR in regression of various hamartomatous growths is a newer modality in the management of TSC.

These patients must adopt measures for careful 
oral and dental hygiene with regular visits to the dentist in order to eliminate potential irritative factors and ensure the early diagnosis of any possible lesions. ${ }^{10}$ The prognosis of TSC depends on the severity or multiplicity of organ involvement. About a quarter of severely affected infants are thought to die before the age of 10 years and $75 \%$ before 25 years. However, in the case of individuals diagnosed late in life with few cutaneous signs, prognosis depends on the associated internal tumors and cerebral calcifications. $^{7}$

In the present case the patient was diagnosed with Tuberous Sclerosis Complex based on some features such as Hypomelanotic macules, Facial angiofibromas, Cortical and Subcortical Tubers and Subependymal nodules. TSC is one of the etiology for refractory seizures, maintaining the patient on anti epileptic drug plays a main role.

\section{Conclusion}

TSC is a genetic disorder with varying clinical features among which dermatological and neurological manifestations are more prominent. Early diagnosis is important in decreasing the morbidity and mortality of the affected individuals. As it is a multisystem disorder, careful clinical observation is essential, patients affected are advised for regular follow up and counselling.

\section{References}

1. Roach ES. Applying the lessons of tuberous sclerosis: The 2015 Hower Award Lecture. Pediatric Neurology 2016; 63:6-22.

2. Sanem Pınar UYSAL*, Mustafa ŞAHİNTuberous sclerosis: a review of the past, present, and future- Turkish Journal of Medical Sciences- doi:10.3906/sag-2002133.

3. Olubunmi OA. Misdiagnosis of tuberous sclerosis in a Nigerian girl: A case report and review of literature. Ann Afr Med. 2010;9:95-101.
4. Illahi Y, Tanveer S, Khurshid Pasha KA, Naeem A, Ali N. Tuberous sclerosis. Classical presentation in a male patient. NMJ. 2010;2:29-32.

5. Midde ML, Saheb DM. Tuberous sclerosis complex - A case report. Southeast Asian J Case Rep Rew. 2013;2:343-8.

6. Shrestha S, Shrestha S, Ojha AR. Case report on tuberous sclerosis. J Kathmandu Med Coll. 2013;2:208-10.

7. Jankar AN, Palange PB, Purandare VC. Tuberous sclerosis - A case report. Int $\mathbf{J}$ Biomed Res. 2014;5:649-50.

8. Cheng TS. Tuberous sclerosis complex: An update. Hong Kong $\mathrm{J}$ Dermatol Venereol. 2012;20:61-7.

9. $\mathrm{Au} \mathrm{KS}$, Williams AT, Roach ES, Batchelor L, Sparagana SP, Delgado MR. Genotype/phenotype correlation in 325 individuals referred for a diagnosis of tuberous sclerosis complex in the United States. Genet Med. 2007;9:88-100.

10. Hope Northrup, MD, Darcy A. Krueger, $\mathrm{MD} \mathrm{PhD}$, and on behalf of the International Tuberous Sclerosis Complex Consensus Group- Tuberous Sclerosis Complex Diagnostic Criteria Update: Recommendations of the 2012 International Tuberous Sclerosis Complex Consensus Conference- Pediatr Neurol. 2013 Oct; 49(4): 243-254.doi: 10.1016/j.pediatrneurol.2013.08.001

11. Soumyabrata Sarkar, Tanya Khaitan, Rupam Sinha, and Arpita Kabira ${ }^{1}$. Tuberous sclerosis complex: A case report-Contemp Clin Dent. 2016 Apr-Jun; 7(2): 236239.doi: $\quad$ 10.4103/0976237X.183071 